\title{
Proton microprobe results for the partitioning of platinum-group elements between monosulphide solid solution and sulphide liquid
}

\author{
Sarah-Jane Barnes \\ Sciences de la Terre, Universite du Quebec, Chicoutimi, G7H 2B1, Canada. \\ e-mail: sjbarnes@uqac.uquebec.ca \\ Esme van Achterbergh, \\ CSIRO Exploration and Mining, P.O. Box 136, North Ryde, NSW 2113, Australia. \\ e-mail: evachter@laurel.ocs.mq.edu.au \\ Emil Makovicky \\ Geological Institute, University of Copenhagen, DK-1350, Copenhagen, Denmark. \\ e-mail: emilm@geo.geol.ku.dk \\ Chusi Li \\ Sciences de la Terre, Universite du Quebec, Chicoutimi, G7H 2B1, Canada. \\ Department of Geology, Indiana University, Bloomington, USA. \\ e-mail: chusili@yahoo.com
}

\begin{abstract}
Partition coefficients (D) for $\mathrm{Ni}, \mathrm{Cu}$, and platinum-group elements (PGE) between monosulphide solid solution (mss) and Fe-sulphide liquid (liq) have been determined experimentally using an electron microprobe (EMP) to analyze experimental run products. The EMP detection limit is approximately 0.05 weight per cent for the PGE, consequently few results were obtained for Pt and Ir and the precision for Pd and Rh at low concentrations was poor. These run products have been reanalyzed using a proton microprobe (PMP), which has a detection limit between 10 and 50ppm for these elements.

It is now clear that $\mathrm{D}^{\mathrm{mss} / \mathrm{liquid}}$ for all the elements show a strong dependence on the $\mathrm{S}$ content of the run in S-undersaturated and S-saturated runs. However, in S-oversaturated runs the S content of the run does not appear to influence $\mathrm{D}^{\mathrm{mss} / \mathrm{liq}}$. The greater precision of the PMP data establishes that in S-oversaturated runs $\mathrm{D}^{\mathrm{mss} / \mathrm{liq}}$ at $1000^{\circ} \mathrm{C}$ are consistently higher than those at $1100^{\circ} \mathrm{C}$. In contrast, $\mathrm{D}^{\mathrm{mss} / \mathrm{liq}}$ in the S-undersaturated and S-saturated runs are similar at both temperatures. This difference in behaviour is thought to arise because in the S-undersaturated and S-saturated runs the amount of $\mathrm{S}$ in the mss is controlled by the $\mathrm{S}$ content of the run. As the $\mathrm{S}$ content in the mss increases, the number of vacancies in the structure of the mss also increases, and $\mathrm{D}^{\mathrm{mss} / \mathrm{liq}}$ rises. In contrast, in S-oversaturated runs the mss has absorbed the maximum amount of $S$ and thus the $S$ content of the run no longer influences the structure of the mss and hence does not control $\mathrm{D}^{\mathrm{mss} / \mathrm{liq}}$. Thus, the effect of temperature on $\mathrm{D}^{\mathrm{mss} / \mathrm{liq}}$ only becomes apparent in the S-oversaturated runs.

The tendency for Os, Ir, Ru and Rh to partition into mss and the exclusion of Cu, Pt and Pd from mss maybe used to explain a number of phenomena; the zonation of massive sulphide bodies, the tendency for Os, Ir, Ru and to a lesser extent $\mathrm{Rh}$ to be enriched in cumulates with minor sulphides, and the presence of two types of sulphides in mantle nodules (an Os-Ir -rich mss and Cu-Pd rich pentlandite).

The tendency of sulphide liquids to crystallize RuOsIr and Pt-Fe minerals at low $f \mathrm{~S}_{2}$ may explain the enrichment of RuOsIr in ultramafic mafic cumulate rocks in the following manner. Sulphide solubility increases as pressures falls. Thus, sulphide droplets in rising basalt magma could be partly resorbed. The PGM could crystallize from this liquid. If these PGM survive long enough, then they could be incorporated into the early cumulate phases such as olivine and chromite. This would explain both the presence of PGM in many olivine and chromite cumulates and the tendency of more evolved magmas to have high $\mathrm{Pd} / \mathrm{Ir}$ ratios.
\end{abstract}

\section{Introduction}

The exact determination of partition coefficients by experimental work has helped to understand a wide variety of natural processes (e.g. Rollinson, 1993). Many experiments have been carried out to investigate the partition coefficients of the lithophile elements over the past thirty years. In contrast, studies of the partition coefficients for the siderophile elements are sparse. In large part, this has been due to analytical difficulties in determining siderophile element concentrations. These partition coefficients are important since they are used in models of a number of processes. The partitioning of metals between sulphide liquid and monosulphide solid solution (mss) could explain the compositional zonation 

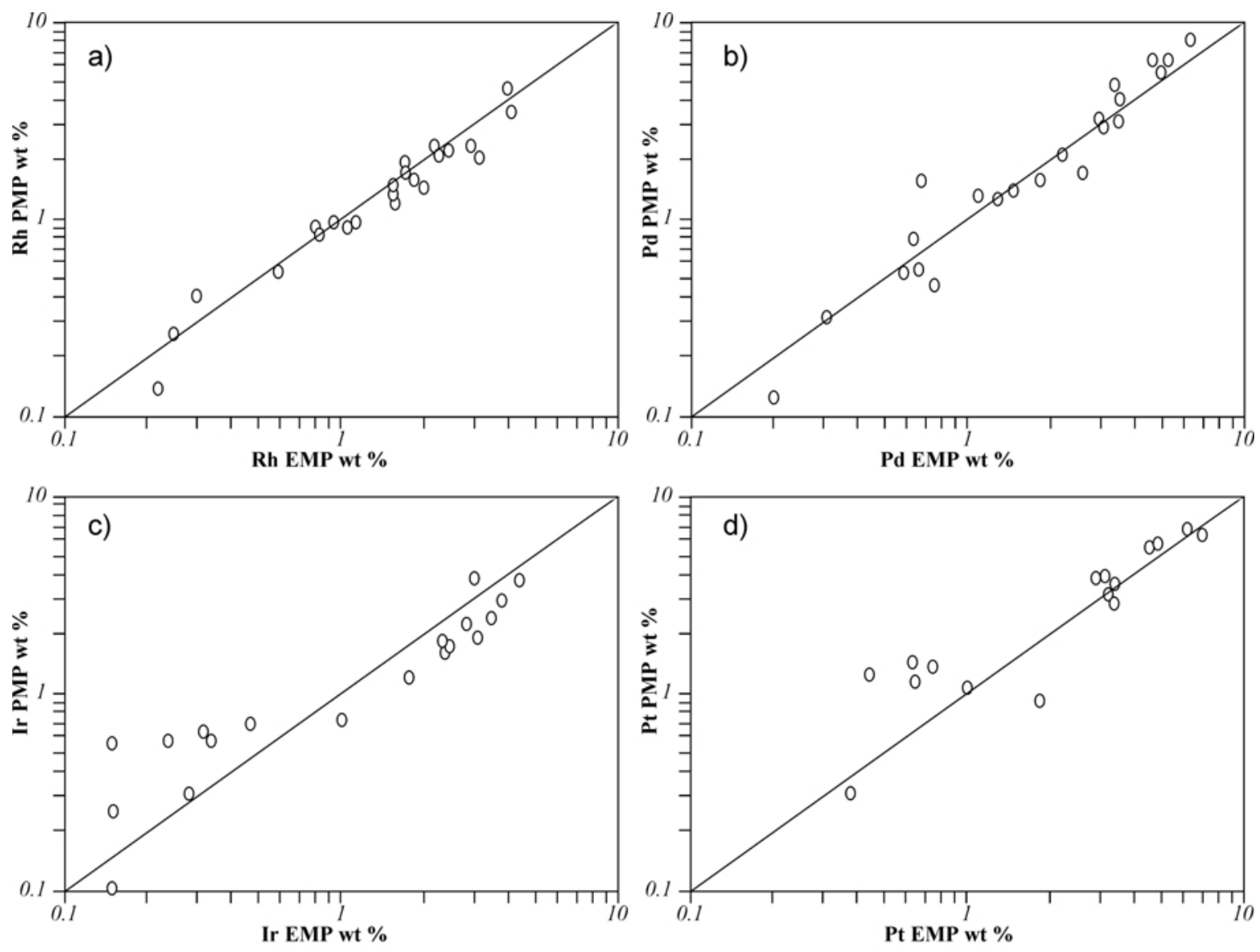

Figure 1. Comparison of the results from the electron microprobe with results from the proton microprobe for: a) Rh, b) Pd, c) Ir, d) Pt.

observed in many magmatic sulphide ores (Barnes et al., 1997b and references therein). Bulanova et al. (1996) have used $\mathrm{D}^{\mathrm{mss} / \mathrm{iq}}$ to interpret the OsIrRu-enriched patterns they found in a sulphide inclusion in a kimberlite diamond. Further, the partitioning of metals among sulphide liquid and metal alloys has been used to speculate on how the Earth's core formed (Jones and Drake, 1986; Jana and Walker, 1997). Walker et al. (1995) have suggested that crystallization of the Earth's inner core as Fe-metal alloy and development of the outer core as a S-bearing metal liquid could result in the outer core being enriched in Pd and Re relative to Os, Ir and Ru. They further speculate that plume-related magmas contain evidence of this because they sample the layer of mantle immediately in contact with outer core, the D" layer, and are enriched in Pd and radiogenic Os.

We attempted to determine the partition coefficients of $\mathrm{Ni}, \mathrm{Cu}, \mathrm{Pd}, \mathrm{Pt}, \mathrm{Rh}$ and $\mathrm{Ir}$ at $1000^{\circ} \mathrm{C}$, and at $1100^{\circ} \mathrm{C}$

Table 1. Run products and the bulk composition of the runs.

\begin{tabular}{|c|c|c|c|c|c|c|c|c|c|c|c|c|c|c|}
\hline $\begin{array}{l}\text { Run \# } \\
\mathbf{T}^{\circ} \mathbf{C} \\
\end{array}$ & $\begin{array}{r}\text { B11-1 } \\
1100 \\
\end{array}$ & $\begin{array}{r}\text { L11-1 } \\
1100 \\
\end{array}$ & $\begin{array}{r}\text { L11-2 } \\
1100 \\
\end{array}$ & $\begin{array}{r}\text { B11-2 } \\
1100 \\
\end{array}$ & $\begin{array}{r}\text { L11-3 } \\
1100 \\
\end{array}$ & $\begin{array}{r}\text { L11-4 } \\
1100 \\
\end{array}$ & $\begin{array}{r}\text { B11-3 } \\
1100 \\
\end{array}$ & $\begin{array}{r}\text { B10-1 } \\
1000 \\
\end{array}$ & $\begin{array}{r}\text { L10-1 } \\
1000 \\
\end{array}$ & $\begin{array}{r}\text { L10-2 } \\
1000 \\
\end{array}$ & $\begin{array}{r}\text { B10-2 } \\
1000 \\
\end{array}$ & $\begin{array}{r}\text { L10-3 } \\
1000 \\
\end{array}$ & $\begin{array}{r}\text { L10-4 } \\
1000 \\
\end{array}$ & $\begin{array}{r}\text { B10-3 } \\
1000 \\
\end{array}$ \\
\hline $\mathrm{S} w \mathrm{wt} \%$ & 31.89 & 33.67 & 35.33 & 36.91 & 38.33 & 39.67 & 41.01 & 31.45 & 33.67 & 35.33 & 36.96 & 38.33 & 39.67 & 40.95 \\
\hline $\mathrm{Fe}$ & 49.85 & 48.33 & 46.67 & 44.96 & 43.67 & 42.33 & 40.95 & 49.16 & 48.33 & 46.67 & 44.91 & 43.67 & 42.33 & 40.95 \\
\hline $\mathrm{Cu}$ & 5.04 & 5.00 & 5.00 & 4.96 & 5.00 & 5.00 & 5.02 & 5.00 & 5.00 & 5.00 & 4.96 & 5.00 & 5.00 & 5.04 \\
\hline $\mathrm{Ni}$ & 4.98 & 5.00 & 5.00 & 4.99 & 5.00 & 5.00 & 4.95 & 4.93 & 5.00 & 5.00 & 5.08 & 5.00 & 5.00 & 4.96 \\
\hline $\mathrm{Pd}$ & 2.08 & 2.00 & 2.00 & 2.11 & 2.00 & 2.00 & 1.96 & 2.09 & 2.00 & 2.00 & 1.96 & 2.00 & 2.00 & 2.05 \\
\hline $\mathrm{Pt}$ & 2.12 & 2.00 & 2.00 & 2.10 & 2.00 & 2.00 & 2.02 & 3.48 & 2.00 & 2.00 & 2.12 & 2.00 & 2.00 & 2.01 \\
\hline $\mathrm{Rh}$ & 2.08 & 2.00 & 2.00 & 1.94 & 2.00 & 2.00 & 2.04 & 1.95 & 2.00 & 2.00 & 1.98 & 2.00 & 2.00 & 2.06 \\
\hline Ir & 1.97 & 2.00 & 2.00 & 2.04 & 2.00 & 2.00 & 2.05 & 1.95 & 2.00 & 2.00 & 2.04 & 2.00 & 2.00 & 2.00 \\
\hline run & mss & mss & mss & mss & mss & mss & mss & mss & mss & mss & mss & mss & mss & mss \\
\hline \multirow[t]{2}{*}{ products } & liquid & liquid & liquid & liquid & liquid & liquid & liquid & liquid & liquid & liquid & liquid & liquid & liquid & liquid \\
\hline & metal & metal & & & S & $\mathrm{S}$ & $S$ & metal & metal & & & $\mathrm{S}$ & $\mathrm{S}$ & S \\
\hline
\end{tabular}



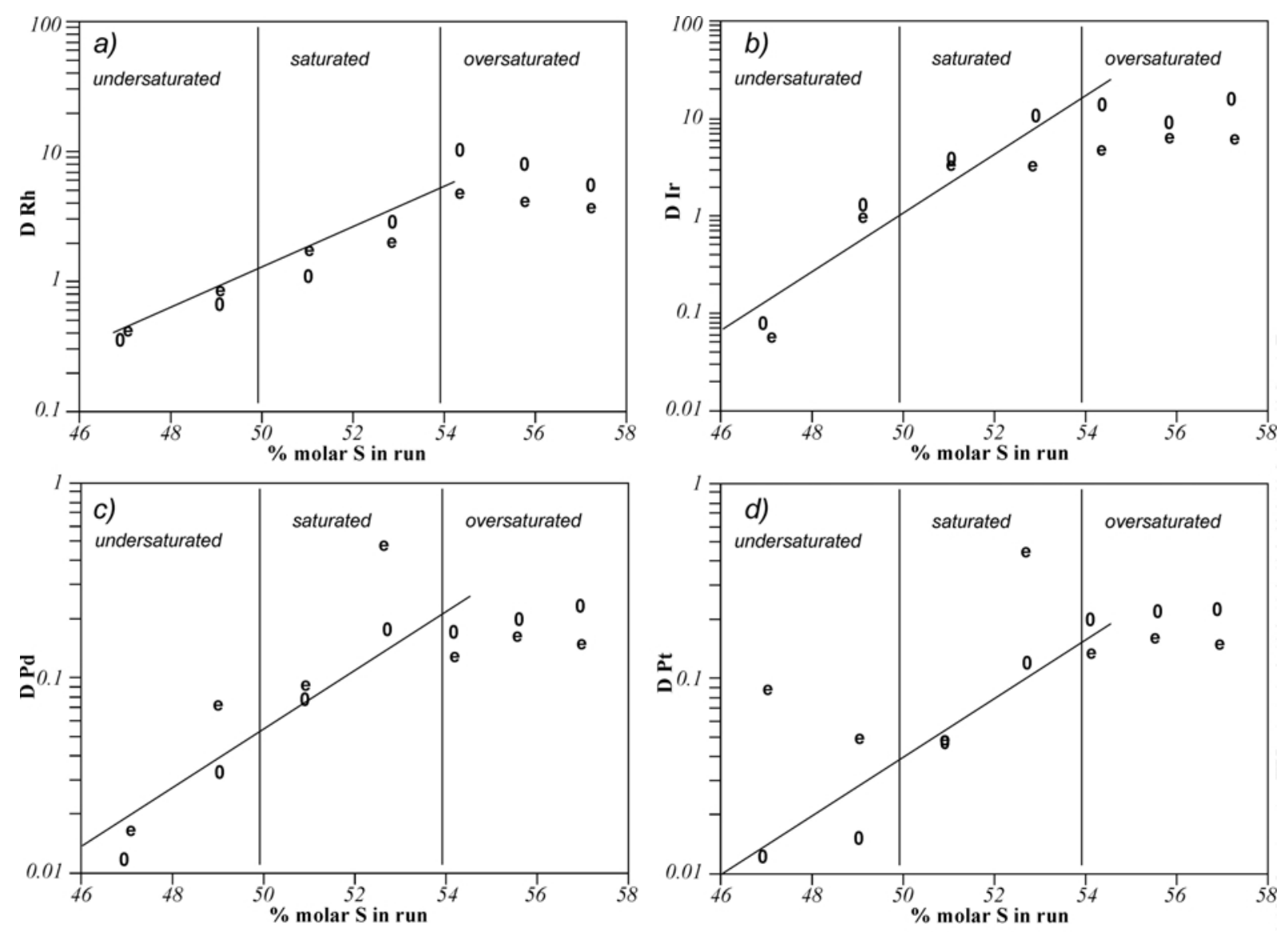

Figure 2. Plot of $\mathrm{D}^{\mathrm{mss} / \mathrm{liq}}$ versus $\mathrm{S}$ content of the run for a) $\mathrm{Rh}$; b) Ir; c) $\mathrm{Pd}$; d) Pt. $\mathrm{o}=$ results for $1000^{\circ} \mathrm{C}$; e $=$ results for $1100^{\circ} \mathrm{C}$. Note the strong correlation between $\mathrm{S}$ content of the run and $\mathrm{D}^{\mathrm{mss} / \mathrm{liq}}$ for S-undersaturated and saturated runs. In S-oversaturated runs $\mathrm{D}^{\mathrm{ms} / \mathrm{liq}}$ is fairly constant and $\mathrm{D}$ at $1000^{\circ} \mathrm{C}$ are higher than at $1100^{\circ} \mathrm{C}$.

among sulphide liquid, mss and metal alloy over a range of $\mathrm{Fe} / \mathrm{S}$ ratios (Li et al., 1996). These results showed that the $\mathrm{D}^{\mathrm{mss} / \text { liquid }}$ of $\mathrm{Ni}, \mathrm{Cu}, \mathrm{Pd}$ and $\mathrm{Rh}$ are strongly controlled by the $S$ content of the run. However, there are only a few results for Pt and Ir because, in many of the run products, these elements were present at concentrations less than the detection limit of the electron microprobe (EMP). Thus, $\mathrm{D}^{\mathrm{mss} / \mathrm{liq}}$ for $\mathrm{Ir}$ at $1000^{\circ} \mathrm{C}$ and $\mathrm{D}^{\mathrm{mss} / \text { liq }}$ for $\mathrm{Pt}$ at $1100^{\circ} \mathrm{C}$ could not be determined. Further, the relationship between $\mathrm{D}^{\mathrm{mss} / \mathrm{liq}} \mathrm{Pt}$ and $\mathrm{S}$ content of the run was ambiguous. These problems have been addressed in this publication by determining the concentrations of platinum-group elements (PGE) by proton microprobe (PMP).

\section{Experimental and Analytical Methods}

In all of the experiments the dry condensed sulphide systems were studied. After examining Kullerud's et al. (1969) phase diagrams the composition of the runs (Table 1) was chosen so as to investigate a range of S-activities. The experimental charges consisted of $150 \mathrm{mg}$ of material. Analytical grade pure elements (metals from Johnson Matthey, S from Fluka AG) were weighed out into silica tubes. The metals were in the form of filed shavings; the sulfur was in the form of crushed crystals. All material was "Specpure" and "High Purity". The silica tubes were then evacuated and sealed. The charges were preheated at $300^{\circ} \mathrm{C}$ for 3 days. The temperature was then raised to $1000^{\circ} \mathrm{C}$ or $1100^{\circ} \mathrm{C}$ in a vertical furnace and kept at the target temperature for 7 and 4 days respectively. Charges were quenched in an ice bath, after which they were opened and the run products mounted in epoxy and polished. A photograph of a typical charge is shown in Li et al. (1996).

After examining the run products (Table 1) in reflected light Li et al. (1996) divided the runs into three groups. Borrowing from the terminology used in silicate systems; S-rich runs containing crystals of native S (representing quenched S-bearing gas), sulphide liquid and mss, are referred to as S-oversaturated; runs with intermediate $\mathrm{S}$ content containing sulphide liquid plus mss, are referred to as S-saturated; and S-poor runs containing metal alloy, sulphide liquid and mss, are referred to as S-undersaturated. The compositions of all these phases were determined by EMP. However, as mentioned in the introduction the results for the PGE were compromised by the high detection limit of the EMP. Therefore, the PGE contents were determined by 
Table 2. Compositions of the sulphide liquid, the mss and Nernst partition coefficients between mss and sulphide liquid

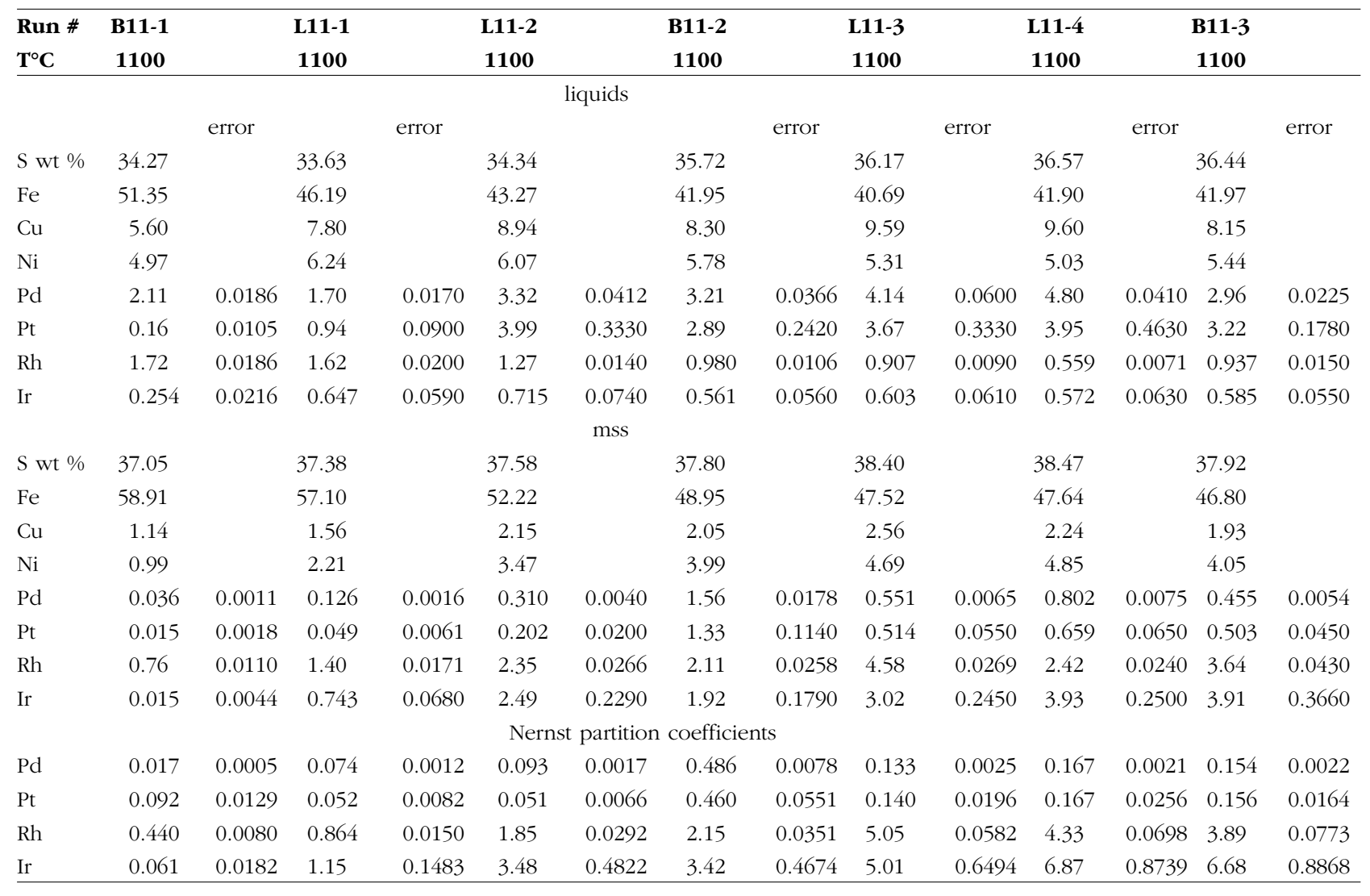

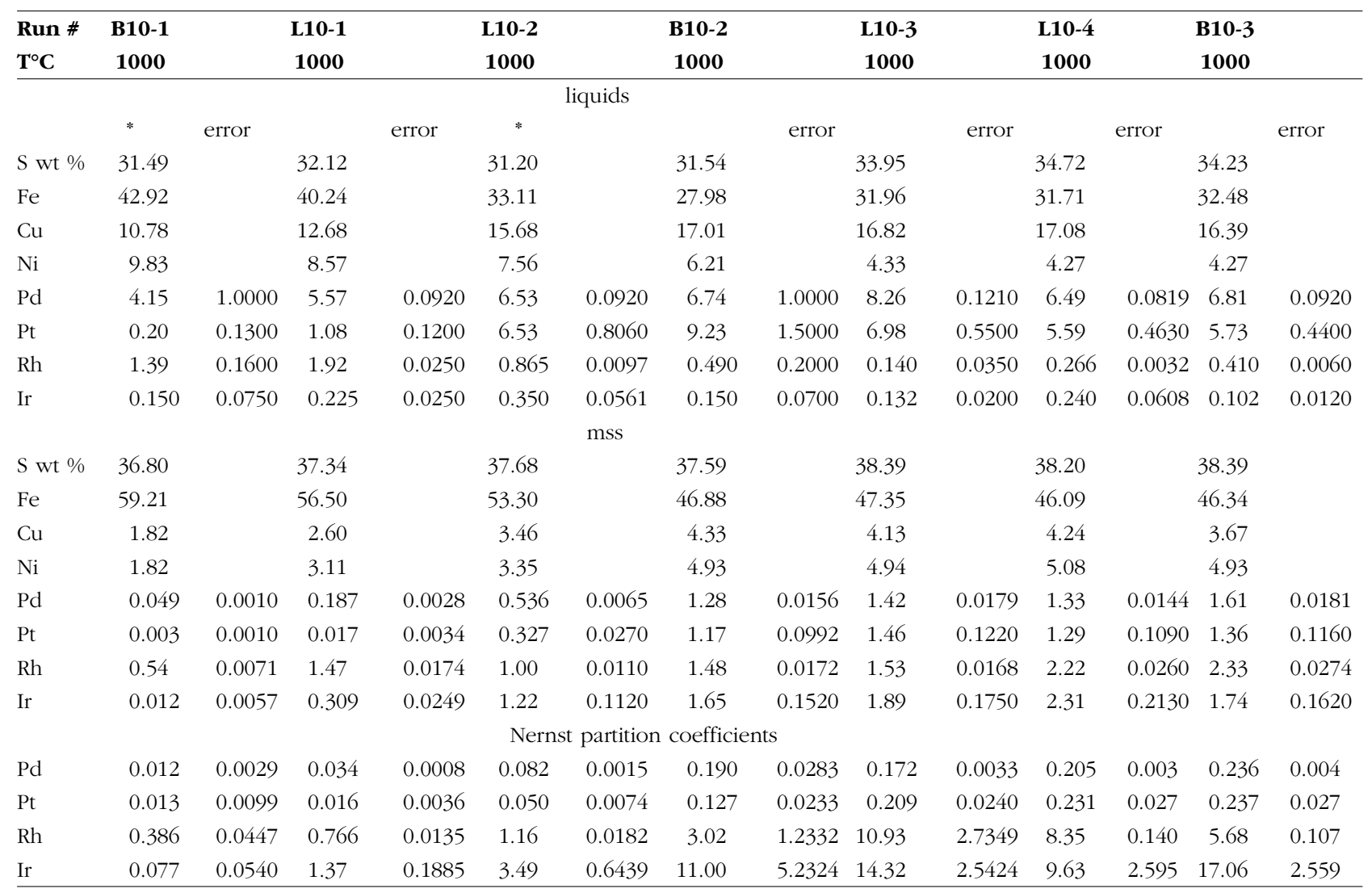

The error on the analyses is based on one standard deviation for 4 determinations of the PGE.

The error on the partition coefficients $=\sigma$ qrt [standard deviation mss/conconcentration mss) $2+$ (standard deviation liquid/concentration liquid)2]*partition coefficent (Potts, 1987 equation 1.22)

* No PMP results available for the liquids, therefore the EMP results were used. 

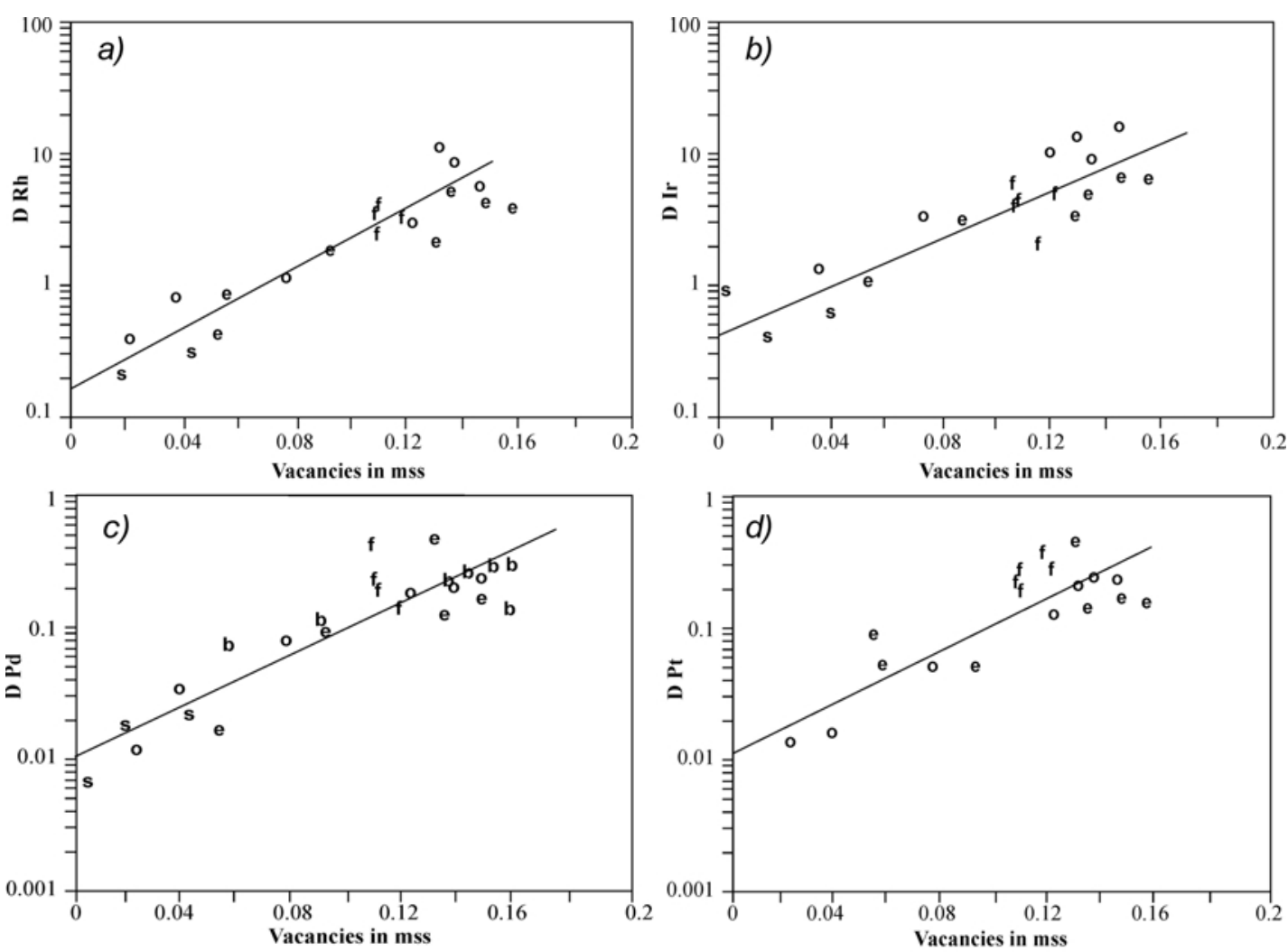

Figure 3. Plot of $\mathrm{D}^{\mathrm{mss} / \mathrm{liq}}$ versus vacancies in mss for a) $\mathrm{Rh}$; b) Ir; c) Pd; d) Pt. o $=$ results for $1000^{\circ} \mathrm{C}$; e $=$ results for $1100^{\circ} \mathrm{C}$. For comparison results from other studies are shown; s= Fleet and Stone (1991), f= Fleet et al. (1993), b=Barnes et al. (1994).

PMP at the Heavy Ion Analytical Facility of the CSIRO, North Ryde, Australia. Protons at energy of $3 \mathrm{MeV}$ were focused to produce a beam of 20 microns in diameter. The beam has a penetration depth of 30 microns. The $\mathrm{X}$-ray spectra are collected by a $\mathrm{Si}(\mathrm{Li})$ energy dispersive detector. The data were processed using the GeoPIXE analysis software correcting for the effects of matrix absorption and secondary fluorescence. Particular care was taken to correct for the matrix effects of $\mathrm{Cu}$. The 99\% confidence detection limit for $\mathrm{Pd}$ and $\mathrm{Rh}$ is about 10ppm, and 30 to 50ppm for Ir and Pt. For more details on the method see Ryan et al. (1990).

\section{Results}

Comparison of PGE concentrations determined by PMP and EMP.

For each phase 4 points were determined and the averages are presented in Table 2 . The relative standard deviations (standard deviation/average) for $\mathrm{Pd}$ and $\mathrm{Rh}$ are generally $2 \%$ or less and those for Ir and Pt, $10 \%$ or less. Comparisons of the PMP results with the EMP results are shown in Figure 1. For Pd and Rh they are in good agreement. In phases where Ir and Pt are present at greater than one weight per cent the PMP and EMP results are in agreement. However, below one weight percent PMP results consistently tend to be higher than the EMP results. The reason for this is not clear. The beam size used in both methods was similar. The penetration depth for the PMP beam is much deeper and it could be argued that the PMP data is more representative. However, the PMP data are the average of only 4 points while the EMP data represent 20 points. Further, the Pd and Rh show good agreement between PMP and EMP results, thus both methods appear to be producing representative averages for these elements.

Table 3. Regression coefficients and equations relating; Nerst partition coefficients and S-content of the run, vacancies in mss and S-content of the liquid

\begin{tabular}{|c|c|c|c|}
\hline Element & $\mathbf{n}$ & $\mathbf{r}$ & Equation \\
\hline \multicolumn{4}{|c|}{ S-content of the run } \\
\hline $\mathrm{Rh}$ & 10 & 0.961 & $\mathrm{D}=\mathrm{e}^{\left(0.373^{*} \mathrm{Sr}-18.2\right)}$ \\
\hline Ir & 10 & 0.918 & $\mathrm{D}=\mathrm{e}^{\left(0.623^{*} \mathrm{Sr}-31\right)}$ \\
\hline $\mathrm{Pd}$ & 9 & 0.924 & $\mathrm{D}=\mathrm{e}^{\left(0.325^{*} \mathrm{Sr}-19.2\right)}$ \\
\hline Pt & 8 & 0.939 & $\mathrm{D}=\mathrm{e}^{\left(0.353^{*} \mathrm{Sr}-21\right)}$ \\
\hline \multicolumn{4}{|c|}{ Vacancies in mss } \\
\hline $\mathrm{Rh}$ & 22 & 0.941 & $\mathrm{D}=0.169 * \mathrm{e}^{\left(24.8^{*} \mathrm{vac}\right)}$ \\
\hline Ir & 25 & 0.887 & $\mathrm{D}=0.6^{*} \mathrm{e}^{\left(18.1^{*} \mathrm{vac}\right)}$ \\
\hline $\mathrm{Pd}$ & 24 & 0.913 & $\mathrm{D}=0.0106^{*} \mathrm{e}^{\left(22.5^{*} \mathrm{vac}\right)}$ \\
\hline Pt & 19 & 0.831 & $\mathrm{D}=0.014^{*} \mathrm{e}^{\left(20.7^{*} \mathrm{vac}\right)}$ \\
\hline \multicolumn{4}{|c|}{ S-content of liquid } \\
\hline $\mathrm{Rh}$ & 22 & 0.854 & $\mathrm{D}=\mathrm{e}^{\left(0.545^{*} \mathrm{Sl}-27\right)}$ \\
\hline Ir & 25 & 0.789 & $\mathrm{D}=\mathrm{e}^{\left(0.367^{*} \mathrm{~S} 1-17\right)}$ \\
\hline $\mathrm{Pd}$ & 24 & 0.858 & $\mathrm{D}=\mathrm{e}^{\left(0.46^{*} \mathrm{Sl}-25.5\right)}$ \\
\hline $\mathrm{Pt}$ & 19 & 0.911 & $\mathrm{D}=\mathrm{e}^{\left(0.437^{*} \mathrm{~S} 1-24.2\right)}$ \\
\hline
\end{tabular}

$\mathrm{n}=$ number of samples; $\mathrm{r}=$ correlation coefficient

$\mathrm{Sr}=\mathrm{S}$ molar content of the run; $\mathrm{vac}=$ vacancies in $\mathrm{mss}$;

$\mathrm{S}=\mathrm{S}$ molar content of the liquid 


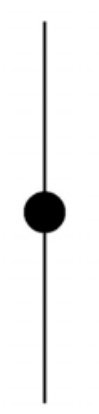

sp
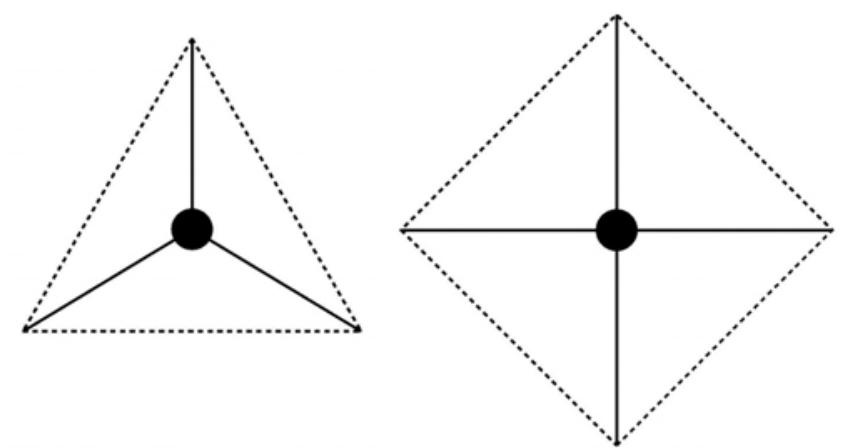

dsp2

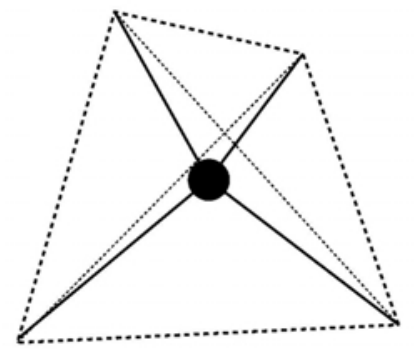

sp3

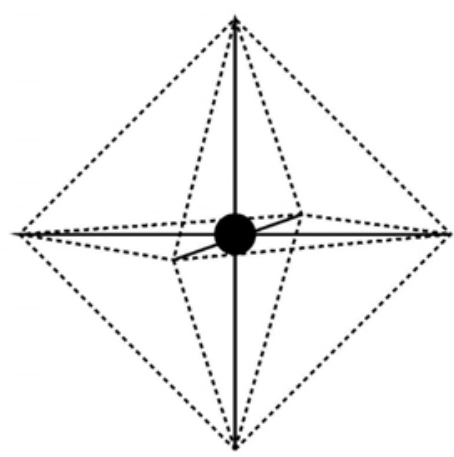

$\mathrm{d} 2 \mathrm{sp} 3$ and $\operatorname{sp} 3 \mathrm{~d} 2$

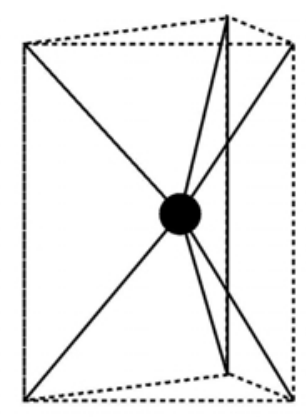

$\mathrm{d} 4 \mathrm{sp}$

Figure 4. Shape of the hybridized orbitals. From Evans (1966).

It is possible that some matrix effect is not being adequately corrected for Ir and Pt in one or both of the methods.

\section{Partition coefficients between monosulphide solid solution and sulphide liquid \\ Rbodium and Iridium}

The $\mathrm{D}^{\mathrm{mss} / \mathrm{liq}}$ changes by over two orders of magnitude from 0.3 to 11 for Rh and 0.06 to 17 for Ir (Table 2). The S-oversaturated runs have the highest $\mathrm{D}^{\mathrm{mss} / \mathrm{liq}}$ and S-undersaturated runs the lowest $\mathrm{D}^{\mathrm{mss} / \mathrm{liq}}$. In $\mathrm{S}$ undersaturated and S-saturated runs there appears to be a strong positive correlation (Table 3 ) between $\mathrm{S}$ content of the run and $\mathrm{D}^{\mathrm{mss} / \mathrm{liq}}$. These relationships may be described by exponential equations (Table 3). The difference in temperature of the runs does not appear to have a strong influence on $\mathrm{D}^{\mathrm{mss} / \mathrm{liq}}$ (Figure $2 \mathrm{a}$ and $\mathrm{b}$ ).

In contrast to the S-undersaturated and S-saturated runs, $\mathrm{D}^{\mathrm{mss} / \mathrm{liq}}$ of the S-oversaturated runs appear to be influenced by temperature and the $\mathrm{D}^{\mathrm{mss} / \mathrm{liq}}$ for both $\mathrm{Rh}$ and $\mathrm{Ir}$ are higher at $1000^{\circ} \mathrm{C}$ than at $1100^{\circ} \mathrm{C}$ (Figures $2 \mathrm{a}$ and b). Another difference between $\mathrm{D}^{\mathrm{mss} / \mathrm{iq}}$ of the S-oversaturated runs and those of the S-undersaturated or saturated runs is that $\mathrm{D}^{\mathrm{mss} / \mathrm{liq}}$ does not appear to be affected by the $S$ content of the run and is fairly constant at any particular temperature.

\section{Palladium and Platinum}

The $\mathrm{D}^{\mathrm{mss} / \mathrm{liq}}$ of Pd and Pt are similar and vary by an order of magnitude from 0.01 to 0.4 . Broadly speaking $\mathrm{D}^{\mathrm{mss} / \mathrm{liq}}$ for both Pd and Pt show the same trends as those of Ir and Rh (Figure $2 \mathrm{c}, \mathrm{d}$ ); i.e. strong positive correlations (Table 3) between $\mathrm{D}^{\mathrm{mss} / \mathrm{liq}}$ and $\mathrm{S}$ content of the runs are present for S-saturated and undersaturated runs. The relationships may be described by exponential equations (Table 3). The $\mathrm{D}^{\mathrm{mss} / \mathrm{liq}}$ for Pd and Pt from run B11-2 and $\mathrm{D}^{\mathrm{mss} / \mathrm{liq}}$ for Pt from run B11-1 are exceptions to this.

The $\mathrm{D}^{\mathrm{mss} / \mathrm{liq}}$ for run B11-2 are higher than the values derived from the other eight runs. Interestingly, the $\mathrm{D}^{\mathrm{mss} / \mathrm{liq}}$ for Pd determined by EMP (0.19, Li et al., 1996) does fall on the trend line. The concentrations of Pt and Pd determined by EMP and by PMP for the liquid are similar suggesting that these results are correct. However, the EMP results for Pd in the mss were half those of the PMP results. As the $\mathrm{D}^{\mathrm{mss} / \mathrm{liq}}$ for EMP results fall on the trend line it seems reasonable to suggest that it is the PMP results for the mss that are incorrect. It should also be noted that the PMP results for Ir and Rh are slightly lower than those obtained by EMP. A possible explanation for this is that the proton beam penetrates to a greater depth than the electron beam and thus the PMP results for this run included some subsurface liquid in the mss analysis. 


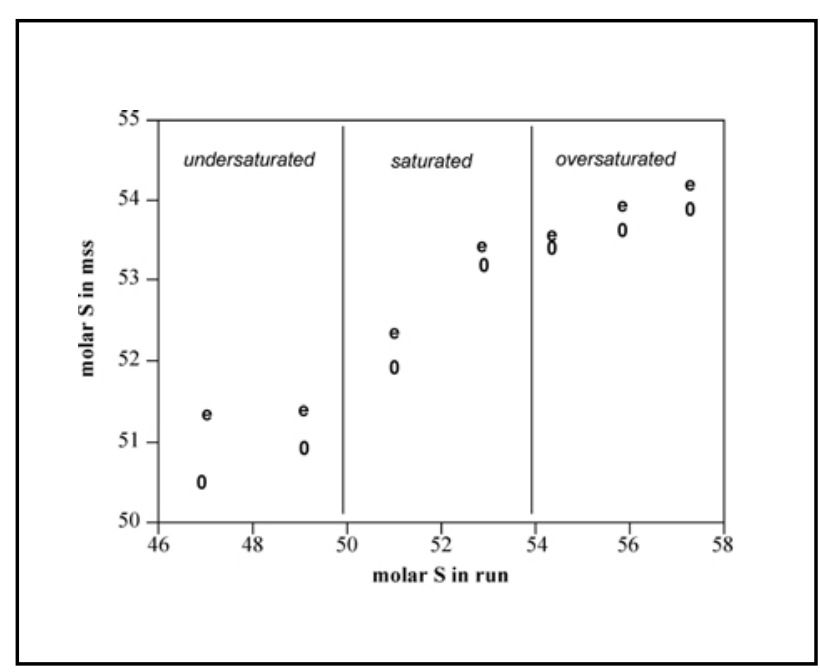

Figure 5. Plot of $S$ content of the run versus $S$ content of the mss. Note the similarities between figures 3 and 5 .

The $\mathrm{D}^{\mathrm{mss} / \mathrm{liq}}$ for Pt in one other run (B11-1) appears to also be higher than would be predicted from the curve calculated from the other eight runs. The Pt content obtained by PMP for the liquid is similar to that obtained by EMP ( 0.16 versus 0.17 ). The Pt content of the mss obtained by PMP is low, $150 \mathrm{ppm}$, and less than the detection limits of the EMP so direct comparison is not possible. The fact that $\mathrm{D}^{\mathrm{mss} / \mathrm{liq}}$ is higher than predicted and the fact the EMP and PMP analyses of the liquid agree suggests that the mss Pt values are too high by a factor of 3. Makovicky et al. (1990) have found that in alloy-bearing runs the Pt from the alloy can be smeared out during polishing of the epoxy mount. Possibly, some Pt from the alloy present in this run contaminated the mss results for this run.

As is observed for Ir and Rh the $\mathrm{D}^{\mathrm{mss} / \mathrm{liq}}$ for the $1000^{\circ} \mathrm{C}$ and $1100^{\circ} \mathrm{C}$ runs are similar. In contrast, for the Soversaturated runs $\mathrm{D}^{\mathrm{mss} / \mathrm{iq}}$ are higher at $1000^{\circ} \mathrm{C}$ than at $1100^{\circ} \mathrm{C}$.

Table 4. Compositions of the alloys and alloy sulphide Nernst partition coefficients.

\begin{tabular}{|c|c|c|c|c|c|c|c|c|}
\hline $\begin{array}{l}\text { Run \# } \\
\mathbf{T}^{\circ} \mathbf{C}\end{array}$ & \multicolumn{2}{|c|}{$\begin{array}{l}\text { B11-1-C } \\
1100\end{array}$} & \multicolumn{2}{|c|}{$\begin{array}{l}\text { L11-1-C } \\
1100\end{array}$} & \multicolumn{2}{|c|}{$\begin{array}{l}\text { B10-1-C } \\
1000\end{array}$} & \multicolumn{2}{|c|}{$\begin{array}{l}\text { L10-1-C } \\
1000\end{array}$} \\
\hline Fe wt $\%$ & \multicolumn{2}{|c|}{13.83} & \multicolumn{2}{|l|}{9.08} & \multicolumn{2}{|c|}{21.15} & \multicolumn{2}{|l|}{16.25} \\
\hline $\mathrm{Cu}$ & \multicolumn{2}{|c|}{0.91} & \multicolumn{2}{|l|}{0.47} & \multicolumn{2}{|l|}{0.68} & \multicolumn{2}{|l|}{1.07} \\
\hline $\mathrm{Ni}$ & \multicolumn{2}{|c|}{0.33} & \multicolumn{2}{|l|}{0.57} & \multicolumn{2}{|l|}{1.51} & \multicolumn{2}{|l|}{1.23} \\
\hline $\mathrm{Pd}$ & \multicolumn{2}{|c|}{0.23} & & & \multicolumn{2}{|l|}{0.61} & \multicolumn{2}{|l|}{0.2} \\
\hline Pt & \multicolumn{2}{|c|}{1.73} & & & \multicolumn{2}{|c|}{26.06} & \multicolumn{2}{|l|}{34.47} \\
\hline $\mathrm{Rh}$ & \multicolumn{2}{|c|}{1.93} & \multicolumn{2}{|l|}{1.83} & \multicolumn{2}{|l|}{8.97} & \multicolumn{2}{|l|}{3.6} \\
\hline Ir & \multicolumn{2}{|c|}{82.18} & \multicolumn{2}{|l|}{87.09} & \multicolumn{2}{|c|}{43.18} & \multicolumn{2}{|l|}{42.92} \\
\hline \multicolumn{9}{|c|}{ Alloy-sulphide liquid Nernst partition coefficients } \\
\hline & & error & & error & & error & & error \\
\hline $\mathrm{Pd}$ & 0.11 & 0.07 & & & 0.15 & 0.04 & 0.04 & 0.03 \\
\hline $\mathrm{Pt}$ & 11 & 2 & & & 130 & 13 & 32 & 3.2 \\
\hline $\mathrm{Rh}$ & 1.1 & 0.33 & 1.1 & 0.36 & 6.4 & 0.42 & 1.9 & 0.30 \\
\hline Ir & 323 & 32 & 135 & 13 & 288 & 28 & 191 & 19 \\
\hline
\end{tabular}

\section{Nickel and Copper}

The results for $\mathrm{Ni}$ and $\mathrm{Cu}$ were reported in $\mathrm{Li}$ et al. (1996) and Barnes et al. (1997b, Figure 2). In these papers it was shown that $\mathrm{D}^{\mathrm{mss} / \mathrm{liq}}$ in the S-Fe-Ni-Cu-PGE system are similar to the values reported by Fleet and Pan (1994) and Ebel and Naldrett (1997) for the S-Fe-Ni$\mathrm{Cu}$ system. The $\mathrm{D}^{\mathrm{mss} / \mathrm{liq}}$ of $\mathrm{Cu}$ covers a narrow range from 0.1 to 0.3 and shows a positive correlation with the $\mathrm{S}$-content of the run. Nickel covers a wider range from 0.1 to 2 and appears to be dependent on the S-content of the run and upon temperature. Equations for these relationships are derived in Barnes et al. (1997b).

\section{Comparison with other published results}

Fleet et al. (1993) have determined $\mathrm{D}^{\mathrm{mss} / \mathrm{liq}}$ for PGE at 1000 to $1040^{\circ} \mathrm{C}$ and a run composition of $53 \%$ molar S. Fleet and Stone (1991) have determined $\mathrm{D}^{\mathrm{mss} / \mathrm{liq}}$ for Ir, $\mathrm{Rh}, \mathrm{Pd}$ and Pt for the Fe-Ni-S system in S-undersaturated conditions at $1000^{\circ} \mathrm{C}$. Values of $\mathrm{D}^{\mathrm{mss} / \mathrm{liq}}$ for Pd have been determined in a number of systems; e.g. Fe-Pd-S at $900^{\circ} \mathrm{C}$ (Makovicky and Karup-Moller, 1993) and the FeCu-Pd-S system at 900 and $1000^{\circ} \mathrm{C}$ (Barnes et al., 1994). In our experiments we have shown that for most of the metals $\mathrm{D}^{\mathrm{mss} / \text { liquid }}$ varies by one to two orders of magnitude and that this variation appears to be dependent on the S-content of the system. Therefore, our results should be compared with other results in terms of D versus molar S-content of the run. However, not all the other published results give the composition of their runs so we cannot make this comparison. As will be discussed below we assume that the tendency of the PGE to enter mss is influenced by the number of vacancies in the mss. (Vacancies are the $\mathrm{x}$ in the $\mathrm{M}_{(1-\mathrm{x}) \mathrm{S}}$ formula and $\mathrm{x}=[\mathrm{S}]-[\mathrm{M}]$, the form of the graph is exactly the same if we plot molar $\mathrm{S}$ in $\mathrm{mss}$ ). $\mathrm{D}^{\mathrm{mss} / \mathrm{iq}}$ versus vacancies in mss for all the available data are shown in Figure 3. The experimental work of Kullerud et al. (1969) indicates that up to 0.25 vacancies are possible in mss at $1100^{\circ} \mathrm{C}$. More recent work by Ebel and Naldrett (1997) indicates a lower number of vacancies but still up to 0.18 for the system Fe-Ni-Cu-S. For the experiments, which include PGE, we calculate the vacancies present in mss to be between 0 and 0.17 , i.e. within the normal range for mss.

In most cases the literature values are in broad agreement with our data and fall on the same trends (Figure 3 and Table 3). An exception to the good coherence of the data is the results for Pt from Fleet and Stone (1991). Their Pt data are higher than ours (0.2 versus 0.013) and, if correct, suggest a difference in behavior between Pd and Pt. However, for the runs in our study and for runs in Fleet et al. (1993) $\mathrm{D}^{\mathrm{mss} / \mathrm{liq}}$ are similar for both Pt and Pd. Therefore, we believe our results are the correct results in this case.

\section{Osmium, Rutbenium and Gold}

Osmium, Ru and Au were not investigated in this study. However, they have been investigated by Fleet et al. (1993) for the S-saturated system between 1000 and 1040 


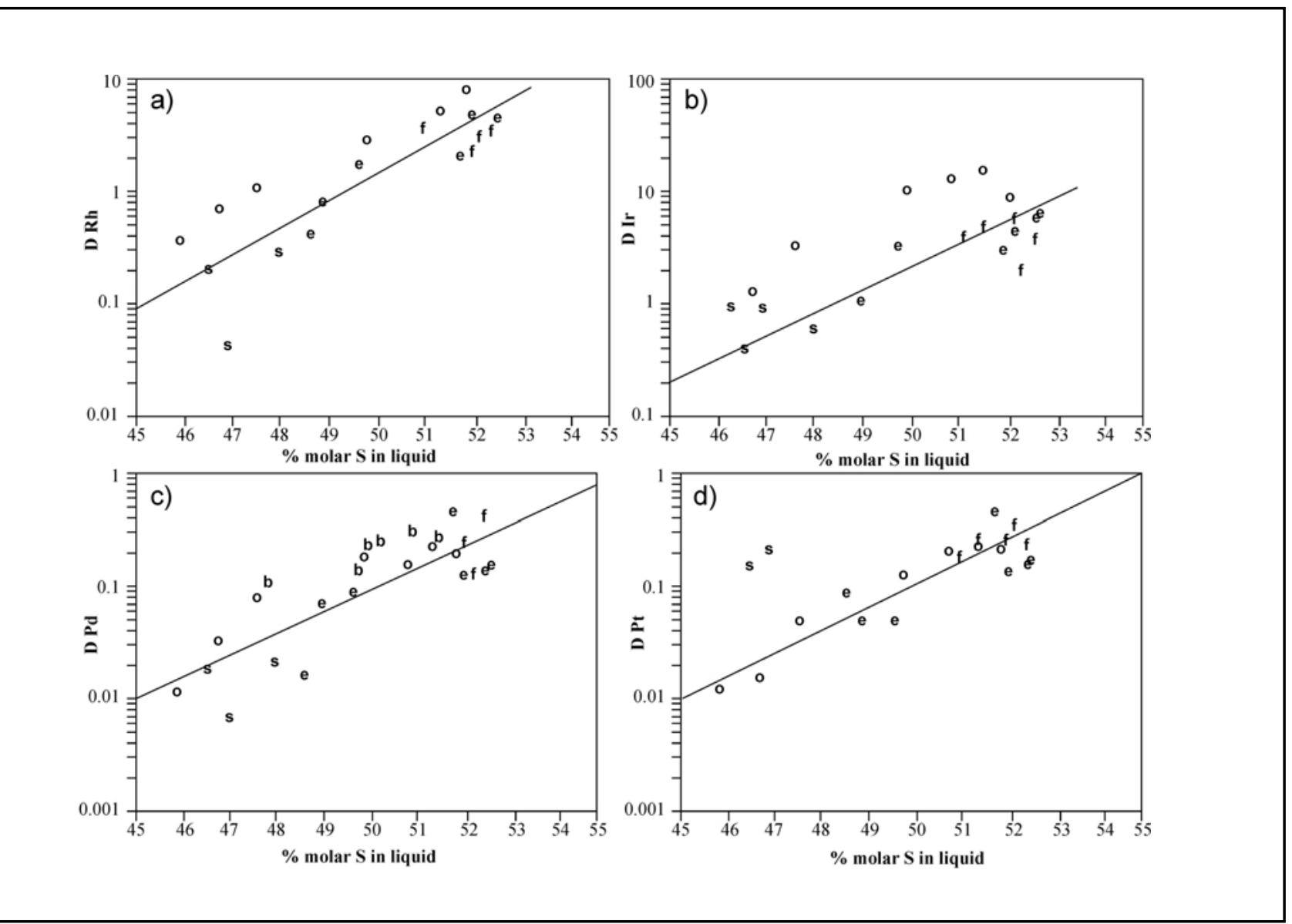

Figure 6. Plot of ${ }^{\mathrm{D}^{\mathrm{mss} / \mathrm{liq}}}$ versus molar $\mathrm{S}$ in the liquid a) $\mathrm{Rh}$; b) $\mathrm{Ir}$; c) $\mathrm{Pd}$; d) $\mathrm{Pt}$

$\mathrm{C}^{\circ}$ Osmium and $\mathrm{Ru}$ were found to be compatible with regard to mss, with partition coefficients similar to Ir. We are currently investigating Os and Ru partition coefficients over a range of S-contents and preliminary results suggest that these elements behave similarly to Ir (Peregoedova et al., in prep). Fleet et al. (1993) found that $\mathrm{Au}$ had a low partition coefficient into mss (0.09).

\section{Partition coefficients between sulphide liquid and alloy.}

An Ir-Pt-Fe alloy formed in the low-S runs. Iridium has very high partition coefficients into this alloy of 130 to 320 (Table 4), while the partition coefficients for Pt are slightly lower (10 to 130). Rhodium is moderately compatible with regard to alloy, with a partition coefficient of 1 to 6. Palladium is not compatible with regard to the alloy and has low partition coefficients (0.04 to 0.11$)$.

These observations are consistent with the work of Fleet and Stone (1991), Jana and Walker (1997) and Brenan and Andrews (2001). All of these studies found Fe-Ir-Pt alloys in their low-S runs and partition coefficients covering similar ranges for $\mathrm{Pt}, \mathrm{Rh}$ and $\mathrm{Pd}$ to our study. The Ir partition coefficients cover a wider range in their experiments (50 to 2000). The composition of the runs and hence composition of the alloys in various experiments reported in the literature varied a great deal and thus more detailed comparison of the type used for the mss partition coefficients is not justified. The salient point to note is that in low-S liquids, alloys tend to form and these alloys generally accept Os, Ir, Ru and in some cases Pt. Pd is generally excluded from the alloys and $\mathrm{Rh}$ shows neutral behavior.

\section{Discussion}

Structure of the mss, and temperature as controls on $D^{\mathrm{mss} / \mathrm{liq}}$

The substitution of trace elements into a solid is normally considered to be controlled by three factors: 1 ) the nature of the bonding; 2) the size of the lattice site; and 3) the charge balance, (Burns, 1970). For Ni, Cu and the noble metals the character of the bonding between $\mathrm{S}$ and metal may be calculated using the formula 100 to $16^{*}$ (electronegativity S-electronegativity $\left.\mathrm{M}\right)+3.5^{*}$ (electronegativity S-electronegitivity M) ${ }^{2}$ (Evans, 1966). This formula suggests that the bonding in sulphides between metals and $\mathrm{S}$ should be largely covalent (Table 5). Covalent bonds are formed by hybridization of the outer electron orbitals. Thus an important feature controlling which metal may substitute for another should be whether the substituting metal can form the same hybridized orbitals as the metal it is replacing. The electron configuration of $\mathrm{Fe}$, Os, Ir, Ru and Rh leads them to adopt $\mathrm{a} \mathrm{d}^{2} \mathrm{sp}^{3}$ configuration (Evans, 1966) 
Table 5. Properties of the Chalcophile Elements

\begin{tabular}{llllll}
\hline Element & $\begin{array}{l}\text { Electrone- Covalent } \\
\text { gativity } \\
\text { character } \\
\text { \% }\end{array}$ & $\begin{array}{l}\text { Preferred } \\
\text { hybridization }\end{array}$ & $\begin{array}{l}\text { Co- } \\
\text { ordination }\end{array}$ & $\begin{array}{l}\text { Covalent } \\
\text { Radius } \\
\text { A }\end{array}$ \\
\hline FeII & 1.8 & 91 & $\mathrm{~d} 2 \mathrm{sp} 3$ & VI & 1.23 \\
NiII & 1.8 & 91 & $\mathrm{dsp} 2$ & IVsq & 1.39 \\
NiII & 1.8 & 91 & $\mathrm{~d} 2 \mathrm{sp} 3$ & VI & 1.39 \\
CuI & 1.9 & 92 & $\mathrm{sp3}$ & IV tet & 1.35 \\
CuII & 1.9 & 92 & $\mathrm{dsp} 2$ & IV sq & 1.35 \\
OsII & 2.2 & 96 & $\mathrm{~d} 2 \mathrm{sp} 3$ & VI & 1.33 \\
IrIII & 2.2 & 96 & $\mathrm{~d} 2 \mathrm{sp} 3$ & VI & 1.32 \\
RuII & 2.2 & 96 & $\mathrm{~d} 2 \mathrm{sp} 3$ & VI & 1.33 \\
RhIII & 2.2 & 96 & $\mathrm{~d} 2 \mathrm{sp} 3$ & VI & 1.32 \\
PtII & 2.2 & 96 & $\mathrm{~d} s p 2$ & IV sq & 1.31 \\
PdII & 2.2 & 96 & $\mathrm{~d} s \mathrm{~s} 2$ & IVsq & 1.31 \\
AuI & 2.4 & 98 & $\mathrm{sp3}$ & IV tet & 1.5 \\
AuIII & 2.4 & 98 & $\mathrm{~d} s p 2$ & IV sq & 1.4 \\
S & 2.5 & 100 & $\mathrm{spd} 4$ & VI tri & 1.04 \\
& & & $\mathrm{sp} 3$ & IV tet & \\
\hline
\end{tabular}

Source Evans (1966)

suitable for octahedral sites (VI fold coordination, Figure 4), but $\mathrm{Pd}$ and $\mathrm{Pt}$ prefer $\mathrm{dsp}^{2}$ configurations (Evans, 1966) suitable for square planar sites (IV fold coordination, Figure 4). Further, $\mathrm{Cu}, \mathrm{Ag}$, and $\mathrm{Au}$ adopt either $\mathrm{dsp}^{2}$ or $\mathrm{sp}^{3}$ hybridizations (Evans, 1966) suitable for either tetrahedral or square planer sites (IV fold coordination, Figure 4). Nickel may adopt either $\mathrm{a} \mathrm{d}^{2} \mathrm{sp}^{3}$ or $\mathrm{dsp}^{2}$ configuration, i.e. either an octahedral or a tetrahedral site. In mss the metals substitute for $\mathrm{Fe}$, which has a $\mathrm{d}^{2} \mathrm{sp}^{3}$ hybridization i.e. VI fold coordination, thus it may be predicted that $\mathrm{Pd}, \mathrm{Pt}, \mathrm{Cu}$, and $\mathrm{Au}$ would be excluded from the structure on the basis of their preference for IV-fold sites. All of the other metals readily adopt an octahedral configuration and should partition into mss. Thus, based on the nature of the hybridized orbitals present we would predict the order of substitution into mss to be Os $\sim \mathrm{Ir} \sim \mathrm{Ru} \sim \mathrm{Rh} \sim \mathrm{Ni}>\mathrm{Pt} \sim \mathrm{Pd} \sim \mathrm{Au} \sim \mathrm{Cu}$. Nickel has a covalent radius, which is considerably larger than the other metals and would have a lower partition coefficient into mss. Based on the large radius of $\mathrm{Au}$, this metal should be the most incompatible. Combining the order based on radii with the order based on hybridization orbitals predicts a substitution in the order Os $\sim \mathrm{Ir} \sim \mathrm{Ru} \sim \mathrm{Rh}>\mathrm{Ni}>>\mathrm{Pt} \sim \mathrm{Pd} \sim \mathrm{Cu}>\mathrm{Au} \quad$ (Table 5). This matches the increase in the value partition coefficients.

In S-saturated and S-undersaturated runs it appears that the greater the S-content of the mss the larger the partition coefficients for the metals into mss are. In contrast, the partition coefficients change very little in S-oversatureated runs (Figure 2 and Barnes et al., 1997b). The S content of mss shows the same relationship to the $S$ content of the run as $\mathrm{D}^{\mathrm{mss} / \mathrm{iq}}$; namely for S-undersaturated and saturated runs there is a strong positive correlation with $\mathrm{S}$ content of the run, but the trend flattens out in S-oversaturated runs (Figure 5).
Simply put, in S-undersaturated and S-saturated runs the amount of $S$ in the mss is controlled by the amount of $S$ in the run, but at some point no more $S$ can be accommodated in the mss and free $S$ forms, therefore in S-oversaturated runs there is no correlation between $S$ content of the run and $S$ content of the mss. The greater the $S$ content of the mss the greater the number of cation vacancies in the mss. It has been suggested that the $\mathrm{D}^{\mathrm{mss} / \mathrm{liq}}$ of $\mathrm{Ni}, \mathrm{Cu}$ and the PGE is controlled by the number of vacancies in the mss structure (Li et al., 1996). This theory can be tested by plotting vacancies in mss versus $\mathrm{D}^{\mathrm{mss} / \mathrm{liq}}$ (Figure 3 ). All of the results (ours plus the literature results) show strong positive correlations (Table 3) indicating that vacancies could indeed control the $\mathrm{D}^{\mathrm{mss} / \mathrm{liq}}$

The reason for this could be that, because all of the PGE are larger than Fe (Table 5), their substitution into mss require distortion of the lattice. The greater the $\mathrm{S}$ content of the mss the more metal vacancies there are in the mss $\left(\mathrm{M}_{(1-\mathrm{x})} \mathrm{S}\right)$. The more vacancies there are the easier it is to distort the lattice and thus the higher the metal partition coefficient into mss. In the case of $\mathrm{Pd}$, $\mathrm{Pt}$, $\mathrm{Au}$ and $\mathrm{Cu}$ their preference for IV fold coordination would lead to an additional tendency to distort the lattice and hence another reason for there to be a relationship between vacancies and partition coefficient. Ballhaus and Ulmer (1995) made a similar point for the partitioning of $\mathrm{Pt}$ and $\mathrm{Pd}$ into pyrrhotite. We would, therefore, predict a positive correlation between $\mathrm{D}^{\mathrm{mss} / \mathrm{iq}}$ and number of vacancies in mss. This correlation is observed for Ir, Rh, Pd, Ni, and Cu. For Pt the trend is less clear. As was mentioned above, the results from Fleet and Stone (1991) are somewhat higher than ours, and if these two points are ignored, then the trend is as predicted.

The results from the S-oversaturated runs make it clear that $\mathrm{D}^{\mathrm{mss} / \mathrm{liq}}$ for the PGE are higher at $1000^{\circ} \mathrm{C}$ than at $1100^{\circ} \mathrm{C}$ (Figure 2). Yet, in the S-undersaturated and S-saturated runs the results for both temperatures are very close, with slightly higher results at $1100^{\circ} \mathrm{C}$. Li et al. (1996) noticed this trend in $\mathrm{D}^{\mathrm{mss} / \mathrm{liq}}$ for $\mathrm{Ni}$, Pd and $\mathrm{Rh}$. The reason for the similarity of the 1000 and $1100^{\circ} \mathrm{C}$ results may be that the mss that forms at $1100^{\circ} \mathrm{C}$ contains more $\mathrm{S}$ and thus more vacancies than the mss that formed at $1000^{\circ} \mathrm{C}$ (Figure 5). Therefore, for a particular $\mathrm{S}$ content of the run there are two competing forces. The effect of lowering the temperature is to raise $\mathrm{D}^{\mathrm{mss} / \mathrm{liq}}$ for the PGE, but at the same time lowering the temperature decreases the $\mathrm{S}$ content of the mss and consequently the number of vacancies. At 1100 and $1000^{\circ} \mathrm{C}$ the net result is, that for S-undersaturated and S-saturated runs $\mathrm{D}^{\mathrm{mss} / \mathrm{iq}}$ are almost equal.

Our model for the partitioning of the metals into mss suggests that the main factor controlling the $\mathrm{D}^{\mathrm{mss} / \mathrm{liq}}$ is the structure of mss (the solid). In contrast, for the system sulphide liquid-metal alloy Jones and Malvin (1990) noted that the partition coefficients into the metals increase with S-content of the liquid. They have proposed a model whereby the partition coefficient into 
the alloy is controlled by the metal tendency to avoid $\mathrm{S}$ in the liquid, rather than the structure of the alloy. We have applied their model to the system mss-sulphide liquid by plotting $\mathrm{D}^{\mathrm{mss} / \mathrm{liq}}$ versus molar $\mathrm{S}$ of the liquid. A positive correlation is observed for all four of the elements, as their model predicts (Figure 6). However, two points lead us to prefer the model based on the structure of the mss. Firstly, their model does not explain why Ir and Rh should be more compatible than Pd and Pt and secondly, there is a stronger correlation between $\mathrm{D}^{\mathrm{mss} / \mathrm{liq}}$ and vacancies than between $\mathrm{D}^{\mathrm{mss} / \mathrm{liq}}$ and S-content of the liquid (Table 3).

\section{Application to natural examples Formation of compositionally zoned massive sulpbides.}

It has been suggested that pyrrohite-rich portions of massive sulphide bodies represent mss cumulates and the chalcopyrite-rich portions represent the fractionated sulphide liquid. Empirical $\mathrm{D}^{\mathrm{mss} / \mathrm{iq}}$ have been calculated based on compositionally zoned sulphides for Sudbury (Li et al., 1993) Noril'sk (Naldrett et al., 1994; Zientek et al., 1994); Cape Smith, Duluth, Alexo and Noril'sk (Barnes et al., 1997a and b) and Duluth (Theriault and Barnes, 1998). The empirical $\mathrm{D}^{\mathrm{mss} / \mathrm{liq}}$ (Ir 2 to 5 ; Rh 2 to 4; Pt 0.05 to 0.1 ; Pd 0.075 to 0.2 ) are similar to the experimental $\mathrm{D}^{\mathrm{mss} / \mathrm{liq}}$ obtained for S-saturated runs. Thus the experimental $\mathrm{D}^{\mathrm{mss} / \mathrm{liq}}$ help define the conditions under which the ore bodies formed. Barnes et al. (1997b) compiled all of the partition data for $\mathrm{Ni}, \mathrm{Cu}$ and PGE available at the time to derive equations relating $\mathrm{D}^{\mathrm{mss} / \mathrm{liq}}$ to $\mathrm{S}$ content of the liquid, and modeled a sulphide ore associated with a komatiite and one associated with a flood basalt. In this modeling it was found necessary to use $\mathrm{D}^{\mathrm{mss} / \mathrm{liq}}$ of the S-saturated runs. It was also necessary to allow for a temperature difference in the formation of the two ores $\left(900^{\circ} \mathrm{C}\right.$ versus $\left.1100^{\circ} \mathrm{C}\right)$ to accommodate the change in the behavior of $\mathrm{Ni}$, which is commonly found to be compatible in tholeiitic-related ores and incompatible in komatiitic-related ores. It is quite probable that the effects of temperature should also be considered on $\mathrm{D}^{\mathrm{mss} / \mathrm{liq}}$ for the noble metals and that $\mathrm{D}^{\mathrm{mss} / \mathrm{liq}}$ will change during crystallization of the sulphide liquid but we have insufficient data at present to evaluate this.

\section{Bebaviour of sulphides during partial melting of the mantle}

Bulanova et al. (1996) found mss enriched in Os, Ir and $\mathrm{Ru}$ in diamonds from kimberlites. This mss could be residual formed by the partial melting of mantle sulphide to form an Fe-mss and a Cu-rich liquid, or it could have crystallized from trapped sulphide melt, which has subsequently migrated away (Bulanova et al., 1996). Recent detailed work on mantle samples indicate that two types of sulphide are present in some mantle nodules (Alard et al., 2000); an Os-Ir rich mss enclosed in silicates (interpreted as residual) and an Cu-Pd rich pentlandite, which is interstitial to the silicates and is interpreted to have been added by basalt melts. The presence of residual mss (enriched in Os, Ir, Ru and Rh) would help to explain the low levels of these elements in picrites and basalts.

\section{Bebaviour of sulphides during ascent of the magma}

Following the work of Wendtland (1982), Mavrogenes and O'Neill (1999) have shown that S solubility is critically dependent on pressure. According to their experimental work most basalts must be saturated in sulphides when they leave their residuum and some sulphides should normally remain in the mantle. The partition coefficients between sulphide liquid and silicate liquid are very high, therefore if sulphides remained in the mantle, then one would not expect any PGE in basalts. The fact that many types of basalt contain some PGE suggests that the basalt must entrain some sulphide droplets. If these sulphide droplets are the product of partial melting of the mantle sulphides they will be enriched in Pd and Pt relative to the other PGE. As the basalts rise and pressure decreases, these sulphide droplets would start to dissolve and the $f \mathrm{~S}_{2}$ in entrained sulphide droplets would fall. If the basalt were transferred directly to the surface, then the sulphides would be resorbed and a non-sulphide bearing, but moderately PGE-rich basalt would erupt. If, on the other hand, the magma moved more slowly PGM could crystallize from the sulphide liquid before the sulphide droplets were completely resorbed. Experimental work indicates that Pt-Ir alloys and RuOs sulphides form in sulphide liquids at low-S concentrations (Peregoedova and Ohnenstetter (sub); Brenan and Andrews, 2001; Fleet and Stone, 1998; Jana and Walker, 1997; Li et al., 1996). Eventually, the sulphide liquid could be completely resorbed, but the PGM consisting largely of Pt-Ir alloys and laurite might continue to survive long enough for them to be incorporated in the early crystallizing phases such as olivine and chromite, much in the manner originally outlined by Hiemstra (1979). This appears to us to be an elegant mechanism for reconciling the observation that $\mathrm{Os}$, $\mathrm{Ir}$ and $\mathrm{Ru}$ and on occasion Pt occur as alloy and laurite inclusions in silicates and oxides cumulates and the fact that the silicate magmas from which they apparently crystallized contain only ppb concentrations of PGE.

The idea that alloys could exist in the presence of a sulphide liquid has been challenged by Peach and Mathez (1996) who found that a sulphide liquid in the presence of Ir alloy contains 4 weight \% Ir. The recent experimental work of Brenan and Andrews (2001) suggests that at least 1 weight $\% \mathrm{Ru}$ is required to saturate a sulphide liquid in laurite or alloys. Both publications suggest that PGM will not crystallize from natural sulphide liquids since no natural liquid contains PGE at the percent level. This argument ignores the sensitivity of the system to the $\mathrm{S}$ content of the liquid (Jana and Walker, 1997). In our runs we found Pt-Ir alloys were present in equilibrium with sulphide liquids 
that contained as little as 0.15 weight \% Ir (Table 2). Fleet and Stone (1991) and Jana and Walker (1997) report results showing Ir concentrations as low as 0.01 $\%$ and less in equilibrium with alloys. Because the different experiments were run under very different conditions and different alloys were produced a more detailed analysis of the problem is not warranted at this time. Suffice to say that we are not aware of any experiments performed at sufficiently low concentrations of PGE to mimic natural systems. Further, apart from Makovicky et al. (1990) the experiments to date have not incorporated elements such as As, Te and $\mathrm{Sb}$ which would greatly effect the solubility of the PGE in the sulphide liquid. Thus, whether the sulphide liquid could become saturated in alloys and other PGM at low S-contents remains an open question.

\section{Bebaviour of sulphides during formation of silicate or oxide cumulate}

Monosulphide solid solution accumulation in silicate or oxide dominated rocks has not been considered until recently. Maier and Barnes (1999) modeled much of the Os, Ir, Ru and Rh enrichment found in the Lower and Critical Zones of the Bushveld Complex as the product of mss accumulation. Peck et al. (2001) use a similar model for the East Bull Lake anorthosite. Andersen et al. (1998) and Arnason and Bird (2000) have carried the model one step further and suggested that zonation of noble metals found in the Skaergaard and Kap Edvard Holm intrusions are the product of alloy crystallization from the sulphide liquid at low- $f S_{2}$. Barnes and Maier (2002) have suggested that the strong enrichment of Pt, Os, Ir, Ru and Rh in the chromitite of the Merensky reef is the result of PGM crystallization from the sulphide liquid. The PGM crystallization was initiated by the interaction between the chromite and the sulphide liquid, which lowered the $f \mathrm{~S}_{2}$ of the sulphide liquid to allow the crystallization of the PGM.

\section{Conclusions}

The $\mathrm{D}^{\mathrm{mss} / \mathrm{liq}}$ for Ir and Rh vary by over two orders of magnitude from 0.06 to 17 . The $\mathrm{D}^{\mathrm{ms} / \mathrm{liq}}$ for Pt and $\mathrm{Pd}$ vary by one order of magnitude from 0.01 to 0.4 . In S-undersaturated and saturated systems there is a strong positive correlation between $\mathrm{D}^{\mathrm{mss} / \mathrm{liq}}$ and the $\mathrm{S}$ content of the runs. In S-oversaturated systems $\mathrm{D}^{\mathrm{mss} / \mathrm{liq}}$ is not strongly influenced by the $S$ content of the runs. The relationship between $\mathrm{D}^{\mathrm{mss} / \mathrm{liq}}$ and $\mathrm{S}$ content of the run and composition of the mss and $\mathrm{S}$ content of the run is similar. This suggests that it is the number of metal vacancies in the mss, which controls $D^{\text {mss/liq }}$ in the S-undersaturated and saturated runs. The more vacancies there are the more the structure can be deformed to allow the entry of the PGE, which are larger than $\mathrm{Fe}$ and need to distort the structure. In the $\mathrm{S}$-oversaturated runs it is clear that $\mathrm{D}^{\mathrm{mss} / \mathrm{liq}}$ is higher in the $1000^{\circ} \mathrm{C}$ runs than in the $1100^{\circ} \mathrm{C}$ runs. In the S-undersaturated and saturated runs, the increase in $\mathrm{D}^{\mathrm{mss} / \mathrm{liq}}$ that one would expect to observe in the $1000^{\circ} \mathrm{C}$ compared with the $1100^{\circ} \mathrm{C}$ runs is offset by a change in the mss structure.

The preference of Ir, Rh, Os and Ru for mss over sulphide liquid can be used to model the compositional zonation commonly found in massive sulphides. Incongruent melting of sulphides in the mantle may lead to the formation of an mss rich in Os, Ir, Ru and Rh in the residuum and a sulphide liquid rich in $\mathrm{Cu}$ and $\mathrm{Pd}$, which is transported from the site of melting by the silicate, melt. As pressure falls the sulphide melt may be resorbed and Os-Ir alloys, laurite and possibly Pt-Ir alloys may crystallize from the S-poor sulphide liquid. These PGM could be incorporated in the first silicates and oxides that form from the basaltic melt and would explain the tendency for Os, Ir and Ru to show compatible behavior during the crystallization of olivine and chromite.

\section{Acknowledgments}

We would like to thank W. Griffin of Macquaire University for facilitating access to the CSIRO proton probe. Financing for the project was truly international, provided by; the Danish Natural Science Research Council, the Natural Science and Engineering Research Council of Canada and the CSIRO, Australia. We would also like to thank two reviewers, Prof. D. Baker and Dr. S. Verryn, for helping us to clarify the original draft, and Mr. Claude Dellaire for drafting the diagrams.

\section{References}

Alard, O., Griffin, W.L., Lorand, J.-P., Pearson, N.J. and Reilly, S. (2000). In-situ analysis of highly siderophile elements and Re-Os isotopes by LAM-ICPMS and LAM-MC-ICPMS reveals the residual and mobile nature of mantle sulfides. Journal of Conference Abstracts, 5, 128-129.

Andersen, J. C.O., Rasmussen, H., Nielsen, T.F.D. and Ronsbo, J.G. (1998) The Triple Group and the Platinova gold and palladium reefs in the Skaergaard intrusions: Stratigraphic and petrographic relations. Economic Geology, 93, 488-509.

Aranson, J.G. and Bird, D.K. (2000). A gold-and platinum-mineralized layer in the gabbros of Kap Edvard Holm Complex: Field, petrographic and geochemical relations. Economic Geology, 95, 945-971.

Ballhaus, C. and Ulmer, P. (1995). Platinum-group elements in the Merensky Reef: II. Experimental solubilities of platinum and palladium in $\mathrm{Fe} 1-\mathrm{xS}$ from 950 to $450^{\circ} \mathrm{C}$ under controlled $f_{\$ 2}$ and $f_{\mathrm{H} 2}$. Geochimica et Cosmochimic Acta, 23,4881-4888.

Barnes, S-J. and Maier, W. D. (2002). The distribution of platinum-group elements and chalcophile elements in the Merensky Reef, Impala Mines, Western Bushveld Complex. Journal of Petrology, 43, 103-128.

Barnes, S-J., Zientek, M.L. and Severson, M.J. (1997a). Ni, Cu, Au and platinum-group element contents of sulphides associated with intraplate magmatism: a synthesis. Canadian Journal of Earth Science, 34, 337-351. Barnes, S-J., Makovicky, E., Makovicky, M. Rose-Hansen, J. and KarupMoller, S. (1997b). Partition coefficients for Ni, Cu, Pd, Pt, Rh and Ir between monosulfide solid solution and sulphide liquid and the formation of compositionally zoned Ni-Cu sulfide bodies by fractional crystallization of sulfide liquid. Canadian Journal of Earth Sciences, 34, 366-374.

Barnes, S-J., Makovicky, E., Karup-Moller, S., Makovicky, M. and RoseHansen, J. (1994). Partition coefficients for Ni, Cu, Pd, Pt, Rh and Ir between monosulfide solid solution and sulfide liquid and the implications for the formation of compositionally zoned $\mathrm{Ni}-\mathrm{Cu}$ sulfide bodies by fractional crystallization of a sulfide liquid. Goldschmidt Conference Edinburgh, Mineralogical Magazine, 58A, 51-52.

Brenan, J.M. and Andrews, D. (2001). High-temperature stability of laurite and Ru-Os-Ir alloy and their role in PGE fractionation in mafic magmas. 
Canadian Mineralogist., 39, 341-360

Bulanova, G.P., Griffin, W.L., Ryan, C.G., Shestakova, Ye, O. Barnes, S-J. (1996). Trace elements in sulfide inclusions from Yakutian diamonds. Contributions to Mineralogy and Petrology, 124, 111-125.

Burns, R.G. (1970). Mineralogical applications of crystal field theory. Cambridge University Press, Cambridge, $224 \mathrm{p}$.

Ebel, D.S. and Naldrett, A.J. (1997). Fractional crystallization of sulfide ore liquids at high temperature. Economic Geology., 91, 607-621.

Evans, R.C. (1966). An introduction to crystal chemistry. Cambridge University Press, Cambridge, $410 \mathrm{p}$.

Fleet, M.E. and Pan, Y. (1994). Fractional crystallization of anhydrous sulfide liquid in the system $\mathrm{Fe}-\mathrm{Ni}-\mathrm{Cu}-\mathrm{S}$, with applications to magmatic sulfide deposits. Geochimica et Cosmochimica Acta, 55, 245-253.

Fleet, M.E. and Stone, W.E. (1991). Partitioning of platinum-group elements in the Fe-Ni-S system and their fractionation in nature. Geochimica et Cosmochimica Acta, 55, 245-253.

Fleet, M.E., Chryssoulis, S.L., Stone, W.E. and Weisener, C.G. (1993). Partitioning of platinum-group elements and $\mathrm{Au}$ in the $\mathrm{Fe}-\mathrm{Ni}-\mathrm{Cu}-\mathrm{S}$ system: Experiments on the fractional crystallization of sulfide melt. Contribution to Mineralogy and Petrology, 115, 36-44.

Heimestra, S.A. (1979). The role of collectors in the formation of platinum deposits in the Bushveld Complex. Canadian Mineralogist., 17, 469-482. Jana, D. and Walker, D. (1997). The influence of sulfur on partitioning of siderophile elements. Geochimica et Comsmochimica Acta, 61, 5255-5277.

Jones, J.H. and Drake, M.J. (1986). Geochemical constraints on core formation in the Earth. Nature, 322, 221-228.

Jones, J.H. and Malvin, D.J. (1990). A nonmetal interaction model for the segregation of trace metals during solidification of Fe-Ni-S, Fe-Ni-P, and FeNi-S-P alloys. Metallurgical Transactions, 21B, 697-706.

Kullerud, G., Yund, R.A. and Moh, G.H. (1969). Phase relations in the CuFe-S, Cu-Ni-S, and Fe-Ni-S systems. Economic Geology Monograph, 4, 323-343.

Li, C., Naldrett, A.J., Rucklidge, J.N. and Kilius, L.R. (1993). Concentrations of platinum-group elements and gold in sulfides from the Strathcona deposit, Sudbury, Ontario. Canadian Mineralogist, 30, 523-531.

Li, C., Barnes, S-J., Makovicky, E., Rose-Hansen, J. and Makovicky, M. (1996). Partitioning of nickel, copper, iridium, rhodium, platinum and palladium between monosulfide solid solution and sulfide liquid: Effects of composition and temperature. Geochimica et Cosmochimica Acta, 60, 1231-1238.

Maier, W. and Barnes, S-J. (1999). Platinum-group elements in silicate rocks of the Lower, Critical and Main Zones at Union Section, Western Bushveld Complex. Journal of Petrology, 40, 1647-1671.

Makovicky, E. and Karup-Moller, S. (1993). The system Pd-Fe-S at $900^{\circ} \mathrm{C}$, $725^{\circ} \mathrm{C}, 550^{\circ} \mathrm{C}$ and $400^{\circ} \mathrm{C}$. Economic Geology, 88, 1269-1278.

Makovicky, E, Karup-Moller, S., Makovicky, M. and Rose-Hansen, J. (1990).
Experimental studies on the phase systems Fe-Ni-Pd-S and Fe-Pt-Pd-As-S applied to PGE deposits. Mineralogy Petrology, 42, 307-319.

Mavrogenes, J.A. and O'Neill, H. St.C. (1999). The relative effects of pressure, temperature and oxygen fugacity on the solubility of sulfide in mafic magmas. Geochimica et Cosmochimica Acta, 63, 1173-1180.

Naldrett A.J., Asif, M., Gorbachev, N.S., Kunhov, V.Y., Stekhin, A.I., Fedorenko, V.A. and Lightfoot, P.C. (1994). The composition of the Ni-Cu ores of the Noril'sk region. In: Lightfoot, P.C. and Naldrett, A.J. (Eds) The Sudbury-Noril'sk Symposium. Ontario Geological Survey, Special Publication, 5, 357-371.

Peach ,C.L.and Mathez, E.A. (1996). Constraints on the formaition of platinum-group element deposits in igneous rocks. Economic Geology, 91, 439-450.

Peck, D.C., Keays, R.R., James, R.S., Chubb, P.T. and Reeves S. J., 2001. Controls on the formation of contact-type platinum-group element mineralization in the East Bull Lake intrusion. Economic Geology, $96,559-581$.

Peregoedova, A. and Ohnenstetter, M. (in press) Collectors of Pt, Pd and Rh in S-poor Fe-Ni-Cu-sulfide system at $769^{\circ} \mathrm{C}$ : Experimental data and application to ore deposits. Canadian Mineralogist.

Potts, P.J. (1987). A Handbook of silicate rock analysis. Chapman Hall, Glasgow. 622 pp.

Rollinson, H.R, (1993). Using geochemical data: Evaluation, presentation, interpretation. Longman, Singapore, $352 \mathrm{p}$.

Ryan, C.G., Cousens, D.R., Sie, S.H., Griffin, W.L., Suter, G.F. and Clayton, E. (1990). Quantitative PIXE microanalysis of geological materials using the CSIRO proton microprobe. Nuclear Instruments and Methods in Physics Research, Secion B, B47, 55-71.

Theriault, R.D. and Barnes, S-J. (1998). Compositional variations in $\mathrm{Cu}-\mathrm{Ni}$ PGE sulfides of the Dunka Road deposit, Dululth Complex, Minnesota: the importance of combined assimilation and magmatic processes. Canadian Mineralogist, 36, 869-886.

Walker, R.J., Morgan, J.W. and Horan, M.F. (1995). ${ }^{187}$ Os enrichment in some mantle plume sources: Evidence for core-mantle interaction? Science, 269, 819-822.

Wendtland, R.F. (1982) Sulfide saturation of basalt and andesite melts at high pressure and temperature. American Mineralogist, 67, 877-885. Zientek, M., Likhachev, A.P., Kunilov, V.E., Barnes, S-J., Meier, A.L., Carlson, R.R., Briggs, P.H., Fries, T.L. and Adrian, B.M. (1994). Cumulus processes and the composition of magmatic ore deposits: examples from the Talnakh district, Russia. In: P. C. Lightfoot and A. J. Naldrett (Editors) The SudburyNoril'sk Symposium. Ontario Geological Survey, Special Publication, 5, 373-392.

Editorial handling: W. D. Maier 